\title{
Obstacles in Formulating a Code of Ethics for Social Workers in Jordanian Institutions
}

\author{
Fakir M. Al Gharaibeh \\ A/Professor of Social Work and Social Policy \\ Department of Sociology, Sharjah University, UAE \\ E-mail: f.gharaibeh@gmail.com
}

Received: September 26, 2011

Accepted: October 24, $2011 \quad$ Published: January 1, 2012

doi:10.5539/ass.v8n1p125

URL: http://dx.doi.org/10.5539/ass.v8n1p125

\begin{abstract}
The major purpose of the study was to examine the obstacles in formulating a code of ethics for social workers in Jordanian institutions and to identify the personal characteristics and professional behaviours of social workers in Jordan.

Qualitative and quantitative methods were used to achieve the objectives of this study. A survey with open and closed questions was distributed randomly to 95 social workers The study found that a substantial numbers of social workers in Jordan (78.6\%) from the sample did not belong to any social work associations. The majority of male and female social workers (29.5\%) have a BSW degree. The research also revealed the obstacles in formulating a code of ethics for social workers in Jordan; those obstacles are the clients, social work institutions, the experience of social workers, weaknesses in the research, and the cultural obstacles in local communities in Jordanian society.

A recommendation arising from the study is that all professional social workers in Jordan need to formulate a national social workers code of ethics as a guide for practice. The code of ethics would have general ethical principles that are based on the core values of social work to be used as a guide for professional behaviour.
\end{abstract}

Keywords: Ethics, Social work, Jordan, Social policy

\section{Introduction}

Values are important in the social work profession. These values should be reflected in a Code of Ethics for social workers; in otherworld, it should be clear what the ethical responsibilities to do what is right are. A Code of Ethics attempts to put these values into the context of every-day practice situations for social workers.

The profession of social work can be traced to 1917, when Mary Richmond, in her book on social diagnosis, formed the parameters of the profession; Richmond's writing reflected her theoretical and practical views and experiences in the field of social work, particularly in school, medicine and family.

The way to work with groups) was formulated by Bharis Quayle. She was the first to teach a groups course at Dmsntezizrv University, where her ideas about human behaviour and leadership in groups were crystallized in her book, the social process in official groups. In 1935, the National Conference of Social Work ratified the way to work with groups and the next year, 1936, the National Association of American, group process was ratified (Konopka,1963). The emergence of the way to work with individuals, and then the emergence of the way to work with groups have certainly contributed to the emergence of the way to organize society, which was first discussed in the United Kingdom, and then in the United States of America, when Robert Lane reported the National Conference of Social Work in 1939. This method was recognized in 1946, along with its recognition of basic programmes in management, research and supervision (Zaki, 1978).

\section{Ethics Are Based on Social Work Practice}

Three methods of social work, individual, group and community, cannot operate alone. Integration between these methods is essential to intervene and minimize the effects of disability; alleviate destitution, deprivation, and escape: remove suffering, anger and resentment; help individuals get out of their isolation; promote them and achieve their adaptation; and give them the opportunities to participate in the community. These are the 
consequences of social and psychological dimensions of individual, family and community circumstances, and the economic, political, and security impacts of events and developments locally, regionally and internationally. Social work is required to intervene to examine, treat, and prevent impact on human life in the light of the values and ethical principles of the social work profession. Global standards for the profession of social work cannot exist without rules derived from values, beliefs and ethics.

Social work aims to develop communities in order to, solve the problems that are beyond the ability of individuals who suffer. Professionals assist people to choose the most appropriate means of effective participation in society by looking for the forces and the various factors that hinder growth and social progress, such as deprivation, unemployment, disease and poor living conditions. Accordingly, the philosophy of social work is related to a moral social philosophy and its roots are linked to religion and humanism since social justice is derived from philosophy, religions and humanity movements, social and natural sciences, and practical experience of social workers.

Therefore, the philosophy of social work preceded the emergence of the profession, which came to based on the pillars of the value and dignity of individual; individual differences, whether between individuals, groups or communities; the individual's right to exercise freedom within the limits of societal values; the individual's right in self-determination without harming the rights of others, social justice between races and religions, love and tolerance (Gharaibeh, 2009).

However, the general practice of social work is based on the use of selective knowledge, professional values, and a broad range of skills to achieve changes at any levels through, according to Achman Hull (1997), three key processes:

1). General practice in social work requires working effectively through the structural building of the institution.

2). General practice requires a variety of professional roles.

$3)$. General practice requires the application of critical thinking skills through the problem - solving process

Values is the third pillar in the practice of social work in which the ethical framework controls the roles of the social worker, and the method used in the provision of services. Ethical and professional standards of the social work profession have manifested the human dimension of this profession, as well as its commitment to achieve well-being, maintain human values and dignity, achieve social justice, and defend vulnerable groups.

In general, values are related to the principles upheld by the profession and the basic mission to individuals, families and communities. The values describe what is acceptable professional practice, in the context of the interaction with clients, to overcome problems, help to bring about change and allow performance of social roles. Values of the profession of social work are often expressed by professional associations of social work (Solomon, 2005). As a result, ethical codes do exist that refer to the commitment to professional practice (Reamer, 2000,1997,1994); these codes clarify the moral, ethical and professional responsibilities as regards the intervention process, which involves the social worker, the beneficiary, and the institution).

A Code of Ethics (the Code), according to the American Association for Social Work -NASW- is meant to be a binding values statement for professional social workers. It describes social workers' ethical conduct in regard to their relationships with beneficiaries, colleagues, practitioners of other professions, and society as a whole. In other words, the Code represents the core values of the social work profession and the standards that characterize social workers. In addition, it determines the rights and duties of the profession. In any case, the Code is not only a set of rules that define and govern the behaviour of professional social workers; it is also general principles to guide and rationalize behaviour, in human, moral and personal terms.

Although prevailing social values have a direct impact on the development of ethical standards (Boland, 2006, Csikai, 1999), personal and professional values are also regarded as an integral part of ethical decision-making (Abramson, 1996; Dolgoff, 2005; Freud \& Krug, 2002; Hopkins, 1997; Mattison, 2000; Pike, 1996). There is a limited research that explores the relationship between moral values and decision-making in the field of social work, I In spite of the importance of this subject. Research investigating the relationship between moral values and decision-makingis lacking. The research that does exist primarily discusses the theoretical aspects of ethical decision-making (Mattison, 2000; Walz \& Ritchie, 2000), describes the types of ethical breaches (Storm \& Aprix, 2000), or provides recommendations for future practice (Dolgoff, 2005; Hoy \& Feigenbaum, 2005; Mattison, 2000).

There are limitations with the existing literature; the complexity and importance of ethical decision-making for social work practice is one area that is lacking in theoretical and practical application. Since it is important to develop a deeper understanding of patterns of ethical decision-making as this process relates to the personal and 
diverse characteristics of professional social workers, it is also important to understand whether social workers decision -making is dependent on standards of code of conduct or affected by other factors.

\section{The Problem of the Study}

This study seeks to identify the obstacles in formulating a professional code of ethics for social workers in Jordanian institutions. The study uses a representative sample of Jordanian social workers.

\section{Aims of Study}

- Identify the personal and professional characteristics of the social workers in Jordan working in Jordanian social work institutions.

- Identify the barriers that may prevent the formulation of a professional code of ethics for social workers working in the social institutions of Jordan.

\section{Background to the Study}

Social workers intervene with people when they have problems in coping with their community. Social workers have a moral and professional obligation to help individuals, groups or communities to take advantage of resources, services and opportunities of social welfare in the community. The profession also requires continuous development of scientific knowledge to understand human behaviour in terms understood by the profession. Those terms - the values and ethical principles of the social work profession form the ethical framework of confidentiality, respect for $\mathrm{n}$ individual's dignity, and right to self-determination A professional code of ethics for social work must needs deal with humans, regardless of colour, race, religion or gender. This study is important because there is no professional code of ethics for social work in Arab / Jordanian society, unlike other professions such as medicine, nursing, and even the media. A code of ethics is established through professional practice, and it, thus, develops over time, according to cultural norms and the changes that occur naturally, the development of the science upon which the profession is based, and the change to approaches and mechanisms of the profession, in addition to the change in priorities. Despite the importance of having a code of ethics, no moves have been made to establish Arab professional code of ethics for the social work profession that clarifies the profession's identity according to the specific Arab culture, defines and describes practice according to the duties performed by social workers, and that establishes the need for social worker, based on the needs of the beneficiaries.

There are many questions about morality and its relationship to human consciousness. For more than a thousand years morality was the bailiwick of the philosophers. Today, Morality is probably more understood through the traditions of a culture (Hopkins 1997). The inclusion of the notion of ethics in the practice of modern professions began by developing specialised codes of conduct to apply to the system in general practice (Dolgoff, 2005).

The objective of a code of ethics is to put forward a set of core values, principles, and standards in order that professionals make ethical decisions. In social work, the following national boides have codes of ethics: the American Association of Social Workers (NASW, 1996), the British Association of Social Workers (BASW, 2003), the Australian Association of Social Workers (AASW, 1999), the Canadian Association of Social Workers (CASW, 1994), the Assembly of New Zealand for social workers (ANZASW), the Association of Singapore for Social Workers (SASW), and the Korean Society of Social Workers (KASW); however' a code does not mean that behaviours to strictly dictated. Canda \& Furman (1999), Haynes (1999), and Smith, McGuire et al, (1991) argue that the personality of social worker is the most influential element in making a decision. Other findings suggest that codes of conduct are not used as the basis for ethical decision-making (Dolgoff \& Skolnik, 1996; Landau, 1999). In a study of ethical decision-making in Psychology, the researchers concluded that psychologists use rules for behaviour as key sources of decision-making; however, their decisions depend on personal values and beliefs more than on codes of conduct (Smith McGuire \&, 1991).

Whatever the many types of codes of ethics are and the professions for which they stand, their general objectives and basic principles in are to protect human rights and dignity, and achieve social justice. These characteristics are key features of these codes of ethics, signifying the significance of social responsibility (Hugman, 2008).

The World Federation for Social Work (IFSW, 2008) confirmed that social work, as a profession, promotes democratic values, human dignity and equality between individuals. Social workers embrace human rights: the social welfare of marginalized groups However, social work seeks to achieve social development in human society as a manifestation of human rights. The struggle for and the pursuit of human dignity and respect in addition to fundamental freedoms allow the development of political, civil, and humanitarian rights (Ife, 2001). 
Other researchers have added that social workers need to fully believe in human rights as the basis for social work practice. Solas (2000) attempts to formulate an awareness that those who demand certain human rights in view of their political and social positions belong to a certain bourgeoisie group or perhaps have a relationship with some important people. However, there are social groups (children, prisoners, the elderly, and women.) that need to be understood.

Hugman (2008) notes the impact of neo-liberalism and its quest to delegitimize the political activity of careers. It is interesting that a code of ethical practices places conditions on employers to provide protection for workers. An Arab moral framework for social work has not yet been identified that takes into account the specific Arab culture. Not having a code of practice restricts the practice by impeding the duties of the social worker as it affects the social worker him/ herself, colleagues, society, and the profession.

The main objective of sustainable human development is to raise the cultural level of individuals so as to have a much safer, more stable and fuller life, exercise hobbies and talents, and cultural well-being, since education and culture are of social and moral benefit, more than material and productivity related benefits (Gharaibeh:2009).

The reduction of government's role and the domination of globalization and its political, and economic effects on human society has made civil society organizations more accepting pf of social community policy and paved the way to spread the culture of human rights, which in turn creates a more balanced human society, The social worker who works through international organizations, (NGOs) groups may adopt the strategies applied there for the purpose of the dissemination and protection of human rights and the exercise of professional work ethics as they represent various cultures and professions through (MPI \& UN) in 2004:

1). Monitoring: the presence in a specific location to monitor events and actions, as regards human rights. Organizations in Geneva at the United Nations provide reports to governments on a regular basis.

2). Persuasion: to convince decision makers of the importance of the work and ublic content messages of non-governmental organisations, and send oral and written letters to the governments and relevant organizations such as the Office of Human Rights Watch in New York (UNDP).

3). Advice and consultancy: to provide legal, scientific and technical advice and consultation through experts concerning certain issues anywhere in the world, but part of a team led by the social worker.

4). Material support in the areas of environment, health and victims of wars, in cooperation with governmental institutions.

5). Collection of the largest possible amount of supporters of human rights issues, through festivals, conferences and marches supporting children, women, education, health, environment and early warning of risk of disasters and crises.

6). Creating and strengthening the relations between nations through the coordination of world activities and festivals for a group of international organizations concerned with certain issues, some of which are permanent, such as the Federal Union, "World Council of Voluntary Agencies," in Geneva.

7). Feedback and guidance for substantive community leaders about issues of national politics.

8). Providing feedback and guidance to the community leaders about national and political issues.

\section{Social Work in Jordanian Institutions}

Institutions in Jordan are divided into two types. Government institutions adopt a needs-based approach and are trying to move towards a right-based approach by improving the practice of social, economic and cultural rights. The Ministry of Social Development, for example, may improve the social and economic rights for Jordanians. It is important for this institution to advise and support people to ask for assistance, and it is also important to persuade them that this is not charity; it is their right as granted by a constitution.

The second type of institution is the NGOs, which made up civil society in Jordan, such as the political parties, professionals' guilds, and student unions. These bodies struggle to create awareness of political and civil rights, by raising awareness through their own newspapers, inviting Jordanians to be members of their organisations, critiquing governmental performance, monitoring human rights in Jordan and reporting their concerns to government.

Governmental and Non-Governmental Organisations may make Jordanians aware not only of their rights, but also of how they can claim their rights. Civil society and governmental organisations, working together, would be more active in protecting, spreading awareness of, and practicing rights for all Jordanians, particularly marginalised groups; and it would also encourage equality, non-discrimination and social justice. 
The data indicate that most needy Jordanians and their families seek social, cultural, and economic rights more than political and civil rights. However, this is also the beginning of a process to claim civil and political rights of Jordanians. Most needy families are uneducated; therefore, they do not know how they can get access to stakeholders at the state or institution level.

Social workers either working with clients or participating in social policy in Jordan means that social workers can play an important role in changing the social system, if they adopt a rights-based approach,. Social workers would thus evolve a relatively greater political role as they encounter unfair policies. Ultimately social work is a vehicle to articulate human rights.

The similar points and value of the government and non-governmental organizations across the world, and the their humanitarian issues reflect the general policy of human rights regarding women, children, refugees, war, environment, education, poverty, democracy and global and civilian norms within which are the values of humanity, security and peace. Globalised, they form the core of the social work profession, which has values, objectives, methodology, and the common methods of global intervention. Furthermore, researchers, academics, and social workers agree that the role of social work in the lives of individuals and human societies is important, regardless of religion, ideology, or geography and thus, there is a need for the drafting of ethical, professional and social code of ethics that regulates the rights, duties and responsibilities of the parties involved in the interference process, the beneficiary, social worker or social institution.

Social work as professional work needs a framework of social legislation related to women, children, prisoners, and aged people. It also draws on knowledge of human growth and social development and works to resolve social conflict, mediation, community development and peace building, and to promote social justice and the enhancement of individual and public welfare. The law guarantees rights and their application. Legal principles and social work practice can together support human growth, promote social development, and advocate peaceful relationships. Both law and social work are concerned with justice, human welfare, issues of diversity, self-determination and independence which create a suitable environment for growing human rights (Moshe 2001).

Social work has played a significant role in dealing with social problems, such as family problems, crime, unemployment, poverty, refugees, and furthering the principles of human rights. Social workers deal with many marginalized groups in society. They work to solve their problems within the changing social system and develop social programs in line with the values, theory, and practice of the profession (IFSW 2002). However code of ethics could be considered as an aspect of framework of social legislation that is necessary for social work profession.

\section{Methodology and Procedures}

The Study population and Sample

The study population consists of all social workers working in Jordan during the period from 25/7/2009 till $5 / 10 / 2010$, having the job title of "social worker", and holding an academic degree in social work. 95 social workers were selected by simple random number tables from those working in public and private social institutions

To achieve the objectives of this study, the researcher prepared a questionnaire consisting of (10) open-ended questions: The researcher gave the target sample of social workers the opportunity target to answer them.

\section{Results and Discussion}

Table (1) shows the personal and professional characteristics of social workers working in social institutions. The current study depends on the members of the total sample of this study, depending on the different variables of age, educational level, gender (male / female) between these individuals.

As shown in Table (1), the proportion of female workers in the field of social work is higher than their counterpart's male members the total sample of this study, and the vast large majority of males and females have a bachelor's degree, at the same time. The table shows that there is also a simple proportion of those holding the old high school who are still performing the role of in for the social worker in the Jordanian institutions.

According to table (2), it appears that the vast majority of social workers in Jordanian institutions, from the members of the sample study, do not belong to associations of social work, and this, in turn, weakens the ability of social workers to know the bases and systems of these associations and mechanisms of action for these associations and weakens their professionalism. 
Table (3) describes the percentage of Jordanian social worker's answers to the questions: Are you aware of any ethics written for social work practice by the institution where you are working in?

Table (3) the extent of social workers awareness of any written ethics for social work practice

It is clear from the percentages recorded in Table (3), the vast majority of social workers in this study don't have any prior knowledge of the ethics written for social work practice. This may be that this is in line with what was brought by the previous table, that the vast majority of specialist social workers in Jordan do not belong to the social associations.

Second, the findings of the obstacles of drafting a professional code of ethics:

This section deals with obstacles that may face social workers in Jordan, from the point of view of the specialists in the current sample.

Respondents working in Jordanian institutions, when asked about the difficulties or obstacles that prevent the formulation of a professional code of ethics. Their answers were divided into the following categories:

1). Difficulties related to Clients:

- Lack of clients' understanding of the importance of the social worker's role.

- The difficulty of obtaining accurate information from the beneficiary, especially if the information is personal.

- Some clients force the social worker to behave unethically because of some misconduct of the client.

- Social workers faced difficulties associated with the traditions and customs of beneficiaries.

2). Difficulties in the working environment of social institutions:

- Lack of independence of the social worker; it is difficult to apply the principle of confidentiality

- Inability to apply the principles of personal interview.

- The lack of an independent office for the social worker: the absence of privacy in the institution.

- Lack of provision of courses and organized training for social workers.

- Difficulties relating to lack of community understanding of the role of social workers.

- Lack of incentives for social workers.

- The routines made necessary due to poor policies of institutions.

- Lack of a mechanism to introduce specialists and their role.

Training is not a priority for institutions, from the perspective of Jordanian social workers. The findings of social research in the field of social work suggest that training in professional ethics affects the attitudes of social workers, the beneficiaries, and decision-making, particularly for those working in hospitals (Csikai, 1999; Boland, 2006). Ethics and training are important steps towards the acquisition of skills necessary to manage ethical dilemmas (Dolgoff, 2005). Some social workers indicate that ethical dilemmas arise in practice, but they do not feel they have the skills necessary to manage the ethical problems they may face (Dolgoff, 2005). It is also important to develop an understanding of personal and professional factors that the influence ethical decision-making process by the social worker.

3). Difficulties relating to the experience of social workers in institutions:

- Lack of separation of the work of a social worker from administrative roles in the organization, thereby hindering adoption of certain value-driven decisions.

- The lack of a sufficient numbers of social workers, which affects the nature of the work and thus, the ethics of social work practice.

-Lack of experience in general that is confined in specific areas of social work.

- Lack of specialization in the areas of social work.

- The leadership of social institutions is in the hands of officials who are somewhat distant from the field of social work.

- Lack of experience in preparing and training for specialist skills.

- Lack of specialist understands of roles, in many cases, because social workers in Jordan do not usually hold a degree in social work, but in a relevant discipline such as Sociology and Psychology.

4). Difficulties relating to the weakness of scientific research: 
- There is an absence of professional ethics in curriculum for students of social work.

The absence of the appropriate conditions and necessary tools to conduct research in institutions This is in contrast to western practice. In Canada, for example, ethical decision-making is based on the accreditation standards adopted by the Canadian Association of Schools of Social Work (CASSW, 2004). The curriculum outlines how the students will have an understanding and the ability to apply values and ethics in the practice of social work in order to make professional judgments compatible with equality, social justice, and human dignity. Landau (1999a) indicates that education and practice of social work play a key role in obtaining the values of social work and the professional socialization. Wesley (2002) also suggests that, although students and faculty of social work in Britain can identify the ethical dilemmas and identify conflicting values, they are unable to propose sufficient resolutions to these ethical difficulties.

5). Difficulties regarding the nature of the dominant culture in the community:

-Cultural, social and class differences reflect the ethics of the social worker.

- There is a contrast between what social workers believe and learn and the social constraints, customs and prevailing traditions in traditional societies.

- There is a contrast of the social worker's ethics, in many cases, with the dominant customs and traditions in a society.

Despite the great similarity between the code of ethics adopted by the (IASSW) and the code of conduct produced by (BASW)) and the American and Australian (Strom, 2006), the activities of social workers in one country may not be recognized in another (Sheppard, 2006). Nevertheless, the development of international cross comparisons of the values and principles of the social work profession as well as such declarations as the Universal Declaration of Human Rights (1948), and the United Nations Declaration on Rights of the Child (1959), have led to the globalization of many of these values and principles, making them more acceptable for the world's social work specialists (Healy, 2007; Banks, 2006).

Finally, the western experience in America, Australia, Canada, and New Zealand in the adoption of organizational councils for social work is worthwhile. The General Council for Social Welfare in England, for example, where organizational councils work in a manner almost independent from the government's position, regulate the standards of social work and social welfare. The employment of many social workers social types of council requires the enrolment in the organizational councils as a condition of employment. This is also the case in some states in America and other countries such as Australia and New Zealand. Moreover, the organizational councils have the authority to punish practitioners who violate the "Code of Conduct"; practitioners who contravene the code can be excluded from membership.

Codes of conduct in America, Australia, Canada, and Britain covers six areas: (1) protects the rights and interests of service's users and suppliers; (2) maintains the trust and confidence of service's users and suppliers of health care; (3) strengthens the independence of service users; (4) respects the rights of the beneficiaries of services and ensures that their behaviours do not harm others; (5) maintains public trust and confidence in the social care services; (6) The social worker is responsible for the quality of the work in the Foundation Reference).

Recommendations and Social Policy Implications

In light of the above, this study recommends the following:

To intensify research and studies in the field of social work ethics.

To prepare a professional, ethics training guide for Arab social work specialists.

To require social work specialists to register with a professional association to obtain a certificate to practice.

To coordinate between universities and departments that teach social work and the relevant professional bodies in order to include ethics in university programs, and to agree in advance on the content and methods of the subjects taught in universities.

To choose social workers who have ethical standards and who exhibit good conduct prior to admission to study social work.

\section{References}

Abramson, M. (1996). Reflections on knowing oneself ethically: Toward a working framework for social work practice. Families in Society, 77(4), 195-201.

Australian Association of Social Workers (AASW). (1999). Code of Ethics. 
Boland, K. (2006). Ethical decision-making among hospital social workers. Journal of Social Work Values and Ethics, 3. [Online] Available: http://www.socialworker.com/jswve (April 2, 2006)

British Association of Social Workers. (BASW). (2003). Code of ethics for social work. Birmingham.

Canadian Association of Social Workers (CASW). (1994). Code of ethics. Ottawa.

Canda, E. R. \& Furman, L. D. (1999). Spiritual diversity in social work practice: The heart of helping. New York: The Free Press.

Connecticut Association of School Social Workers (CASSW). (2004). Standards of Accreditation. Ottawa, ON. Author.

Csikai, E. L. (1999). The role of values and experience in determining social workers' attitudes toward euthanasia and assisted suicide. Social Work in Health Care, 30(1), 75-95. http://dx.doi.org/10.1300/J010v30n01_05

Dolgoff, R. \& Skolnik, L. (1996). Ethical decision-making in social work with groups: An empirical study. Social Work with Groups, 19(2), 49-65. http://dx.doi.org/10.1300/J009v19n02_05

Dolgoff, R., Loewenberg, F. M. \& Harrington, D. (2005). Ethical decisions for social work practice (7th Ed.). Belmont, CA: Brooks/Cole.

Freud, S. \& Krug, S. (2002). Beyond the code of ethics, Part I: Complexities of ethical decision-making in social work practice. Families in Society, 83(5), 474-482.

Gharaibeh, Fakir. (2009). The areas of social work. Amman / Jordan: Dar Wael.

Haynes, D. T. (1999). A theoretical integrative framework for teaching professional social work values. Journal of Social Work Education, 35(1), 39-50.

Healy, L. M. (2007). Universalism and cultural relativism in social work. International Journal of Social Work, 50(1):11-26. http://dx.doi.org/10.1177/0020872807071479

Hodge, D. R. (2005). Spirituality in social work education: A development and discussion of goals that flow from the profession's ethical mandates. Social Work Education, 24(1), 37-55. http://dx.doi.org/10.1080/0261547052000324982

Hopkins, W. E. (1997). Ethical dimensions of diversity. London: SAGE Publications.

Hoy, J. \& Feigenbaum, E. (2005). Ethics in community care: Making the case for ethics consultants in community mental health centers. Community Mental Health Journal, 41(3), 235-250. http://dx.doi.org/10.1007/s10597-005-4995-9

Hugman, R. (2008). An ethical perspective on social work, in M, Davies (ed.) The Blackwell Companion to Social Work (third edition), London: Blackwell, 442-448.

Ife, J. (2001). Human Rights and Social Work: Toward Rights-Based Practice, 1st edn. Cambridge University Press, Cambridge.

International Federation of Social Workers (IFSW). (2008). Code of ethics, Statement of principles: Berne, Switzerland.

Konopka. G. (1963). Social Group Work: A Helping Process. Prentice Hall, Englewood Cliffs, NT.

Landau, R. (1999b). Ethical judgment, code of ethics and supervision in ethical decision-making in social work: Findings from an Israeli sample. Journal of Applied Social Sciences, 23(2), 21-29.

Mattison, M. (2000). Ethical decision-making: The person in the process. Social Work, 45(3), 201-212.

Ministry of Planning International and United Nations (MPI \& UN). (2004). Amman. Jordan Human Development Report.

National Association of Social Work (NASW). Encyclopedia of Social Work. Washington, D.C., NASW Press, 1511-1520.

National Association of Social Workers (NASW). (1999). Code of ethics of the National Association of Social Workers. Washington, DC.

National Association of Social Workers (NASW). (2006). Licensed social workers in the U.S., 2004. [Online] Available: http://workforce.socialworkers.org/studies/natstudy.asp (April 20, 2006) 
Perkins, D. V., Hudson, B. L., Gray, D. M. \& Stewart, M. (1998). Decisions and justifications by community mental health providers about hypothetical ethical dilemmas. Psychiatric Services, 49(10), 1317-1322.

Pike, C. K. (1996). Development and initial validation of the Social Work Values Inventory. Research on Social Work Practice, 6(3), 337-352. http://dx.doi.org/10.1177/104973159600600305

Reamer, F. G. (1994). Social work malpractice and liability. New York: Columbia University Press.

Reamer, F. G. (1997). Ethical standards in social work: The NASW code of ethics. Encyclopedia of Social Work, 19th edition. Washington, DC: National Association of Social Workers.

Reamer, F. G. (2000). Ethical Issues in Direct Practice, in P. Allen-Meares and C. Garvin (eds). The handbook of social work direct practice. California: Sage Publication, Inc.

Sheppard, M. (2006). Social work and social exclusion: The idea of practice. Aldershot: Ashgate.

Smith, T. S., McGuire, J. M., Abbot, D. W. \& Blau, B. I. (1991). Clinical ethical decision-making: An investigation of the rationales used to justify doing less than one believes one should. Professional Psychology. Research and Practice, 22(3), 235-239. http://dx.doi.org/10.1037/0735-7028.22.3.235

Solomon, Hussein et al. (2005). The general practice in social work with the group, institution, society. Beirut: the glory of the institution of the university studies, publishing and distribution.

Strom-Gottfried, K. \& D'Aprix, A. (2006). Ethics for academics. Journal of Social Work Education, 25(3): 225-244. http://dx.doi.org/10.1080/02615470600565046

Walz, T. \& Ritchie, H. (2000). Gandhian principles in social work practice: Ethics revisited. Social Work, 45(3), 213-222.

Zaki Younis. (1978). Social Work and Social Change. World of Book Press, 1Sted, Cairo.

Table 1. The findings of personal and professional characteristics

\begin{tabular}{|l|l|l|}
\hline Age & Male $\%$ & Female $\%$ \\
\hline $20-29$ & 21.1 & 22.1 \\
\hline $30-39$ & 18.9 & 22.1 \\
\hline $40-49$ & 2.1 & 9.5 \\
\hline $50+$ & 3.2 & 1 \\
\hline Total & 45.3 & 45.7 \\
\hline Education & Male \% & Female $\%$ \\
\hline PhD & 1 & 0 \\
\hline MA & 7.4 & 6.3 \\
\hline BA & 29.4 & 29.5 \\
\hline Diploma & 4.2 & 11.5 \\
\hline High School & 3.2 & 7.4 \\
\hline Total & 45.3 & 54.7 \\
\hline
\end{tabular}

Table 2. Membership of social workers in the social work associations

\begin{tabular}{|l|l|}
\hline SW Association Membership & \multicolumn{2}{|c|}{$\%$} \\
\hline Member & 23.2 \\
\hline Not Member & 76.8 \\
\hline Total & 100 \\
\hline
\end{tabular}

Table 3. Are you aware of any ethics written for social work practice by the institution where you are working in?

\begin{tabular}{|l|l|}
\hline Aware of any ethics written for social work & $\%$ \\
\hline Yes & 24.2 \\
\hline No & 75.8 \\
\hline Total & 100 \\
\hline
\end{tabular}

